

\title{
THE EFFECT OF MAGNETIC PEAKING ON THE DYNAMIC APERTURE
}

\author{
T. Garavaglia and Rae Stiening \\ Superconducting Super Collider Laboratory* \\ Accelerator Division \\ 2550 Beckleymeade Avenue \\ Dallas, TX 75237
}

March 1990

\section{DISCLAIMER}

\begin{abstract}
This report was prepared as an account of work sponsored by an agency of the United States Government. Neither the United States Government nor any agency thereof, nor any of their employees, makes any warranty, express or implied, or assumes any legal liability or responsibility for the accuracy, completeness, or usefulness of any information, apparatus, product, or process disclosed, or represents that its use would not infringe privately owned rights. Reference herein to any specific commercial product, process, or service by trade name, trademark, manufacturer, or otherwise does not necessarily constitute or imply its endorsement, recommendation, or favoring by the United States Government or any agency thereof. The views and opinions of authors expressed herein do not necessarily state or reflect those of the United States Government or any agency thereof.
\end{abstract}

* Operated by Universities Research Association, Inc., for the U.S. Department of Energy under Contract No. DE-AC02-89ER40486.

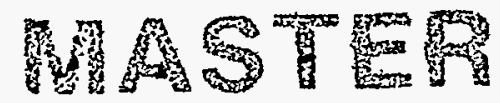




\section{DISCLAIMER}

Portions of this document may be illegible in electronic image products. Images are produced from the best available original document. 
SSCL-260

\title{
THE EFFECT OF MAGNETIC PEAKING ON THE DYNAMIC APERTURE
}

\author{
T. Garavaglia and Rae Stiening \\ Superconducting Super Collider Laboratory* \\ Accelerator Division \\ 2550 Beckleymeade Avenue \\ Dallas, TX 75237
}

March 1990

\section{Introduction}

It has been suggested that the dynamic aperture of the SSC can be increased by a suitable choice of the dipole systematic allowed multipole moments so as to extend the uniform field region of the magnet. In this note the the effect of combinations of $B_{4}$ and $B_{6}$ are considered on the tune shifts. These tune shifts have been calculated using the methods of Refs. [1] and [2]. The results of these calculations are given in Figures 2 through 13.

The magnetic multipole field that results in peaking is found from

$$
B_{y}(x, y)=B_{o} \operatorname{Real}\left[B_{4}(x+i y)^{4}+\dot{B}_{6}(x+i y)^{6}\right]
$$

which produces

$$
\begin{aligned}
B_{y}(x, y) / B_{o}= & B_{4}\left(x^{4}-6 x^{2} y^{2}+y^{4}\right) \\
& +B_{6}\left(x^{6}-15 x^{4} y^{2}+15 x^{2} y^{4}-y^{6}\right) .
\end{aligned}
$$

One can illustrate the peaking effect using Eq. (2) with a suitable choice of the parameters. For $y=0, B_{4}=1$, and $B_{6}=0$ the field $B_{y}(x, 0) / B_{o}$ is positive

* Operated by Universities Research Association, Inc., for the U.S. Department of Energy under Contract No. DE-AC02-89ER40486. 
and increasing with $x$; however, with $B_{4}=1$, and $B_{6}=-4, B_{y}(x, 0) / B_{o}$ rises to a maximum positive value-peaking - and then decreases to negative values for increasing $x$ values. These two. cases are shown in Figure 1 where it is seen that the second combination of parameters has the effect of extending the uniform field region in the horizontal plane of the magnet.

\section{Tune Shift Plots}

An indication of the change in the dynamic aperture can be found from an inspection of the figures indicating the tune shifts associated with injection at different points $(x, y)$ for different choices of the values of $B_{4}$ and $B_{6}$. In these figures, particles are injected on a grid from $x=y=0$ to $x=y=x_{\max }$ with momentum dispersion values of $+\delta p / p, 0$, and $-\delta p / p$. In all of these examples the nominal betatron fractional tune values are $\nu_{x}=0.425$ and $\nu_{y}=0.410$, and all multipole coefficients $B_{i}$, except $B_{4}$ and $B_{6}$, are zero. In each case the values used for $B_{4}, B_{6}, x_{\max }$, and $\delta p / p$ are given in Table 1.

Table 1. Input Values For Tune Shift Graphs

\begin{tabular}{ccccc}
\hline \hline Case & $B_{4}$ & $B_{6}$ & $X_{\max } \mathrm{mm}$ & $\delta p / p$ \\
\hline 20 & 1.0 & 0.0 & 5.0 & $10^{-4}$ \\
21 & 1.0 & 0.0 & 4.0 & $10^{-4}$ \\
22 & 1.0 & 0.0 & 3.0 & $10^{-4}$ \\
23 & 1.0 & -4.0 & 5.0 & $10^{-4}$ \\
24 & 1.0 & -4.0 & 4.0 & $10^{-4}$ \\
25 & 1.0 & -4.0 & 3.0 & $10^{-4}$ \\
26 & 0.1 & -0.4 & 5.0 & $10^{-3}$ \\
27 & 0.1 & -0.4 & 4.0 & $10^{-3}$ \\
28 & 0.1 & -0.4 & 3.0 & $10^{-3}$ \\
29 & 0.1 & 0.0 & 5.0 & $10^{-3}$ \\
30 & 0.1 & 0.0 & 4.0 & $10^{-3}$ \\
31 & 0.1 & 0.0 & 3.0 & $10^{-3}$ \\
\hline \hline
\end{tabular}




\section{Conclusion}

It is clear from the figures, which give a spread in the values of the tune shifts, that there is a marginal improvement in the dynamic aperture for cases 26,27 , and 28 (Figures 8,9 and 10, respectively) where both $B_{4}$ and $B_{6}$ are small. These are to be compared with cases 29, 30 and 31 (Figures 11, 12 and 13, respectively) where $B_{6}$ is zero. However, for the case with $B_{4}=1$ and $B_{6}=-4$ where Figure 1 shows an extension of the region of uniformity of the magnetic field to nearly $5 \mathrm{~mm}$, the dynamic aperture is actually worse than the case with $B_{4}=1$ and $B_{6}=0$. This can be seen when the tune shift plots Figure 2 and Figure 3 for injection out to $5 \mathrm{~mm}$ and $4 \mathrm{~mm}$, respectively, are compared with the corresponding plots case 23 and case 24 (Figures 5 and 6 , respectively) which represent the case with extended field uniformity. We conclude from this study that the peaking effect would not produce a substantial increase in the dynamic aperture. Figures 4 and 7 are provided for continuity, but do not provide significant data. 


\section{REFERENCES}

1. A. Jackson, "Tune Shifts and Compensation From Systematic Field Components," SSC-107, (1987).

2. E. Forest, "Computation of First Order Tune Shifts," SSC-N-322, (1987). 


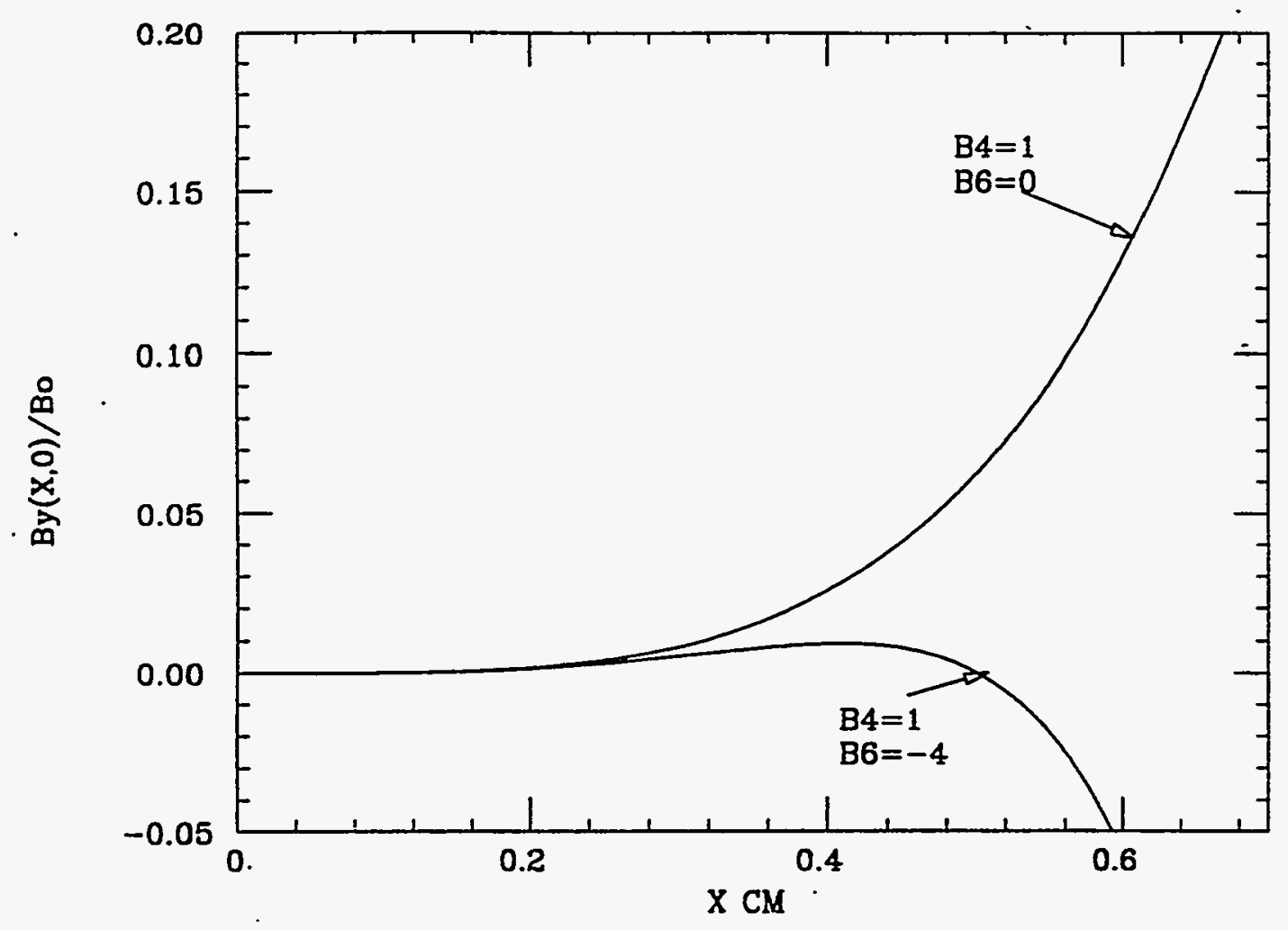

Figure 1: Magnetic field peaking.

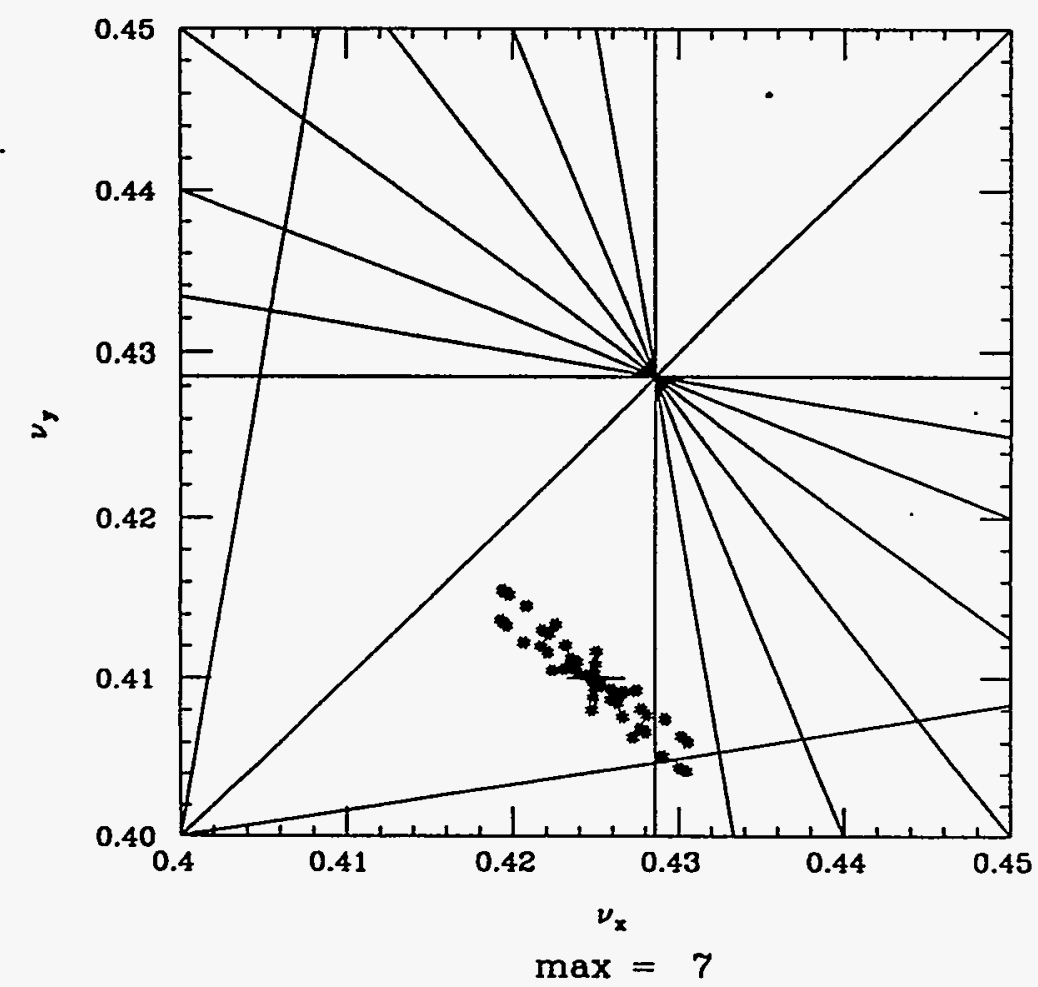

Figure 2: Tune shift 20,4 cm magnet $x=y=0.500 \mathrm{~cm}$. 


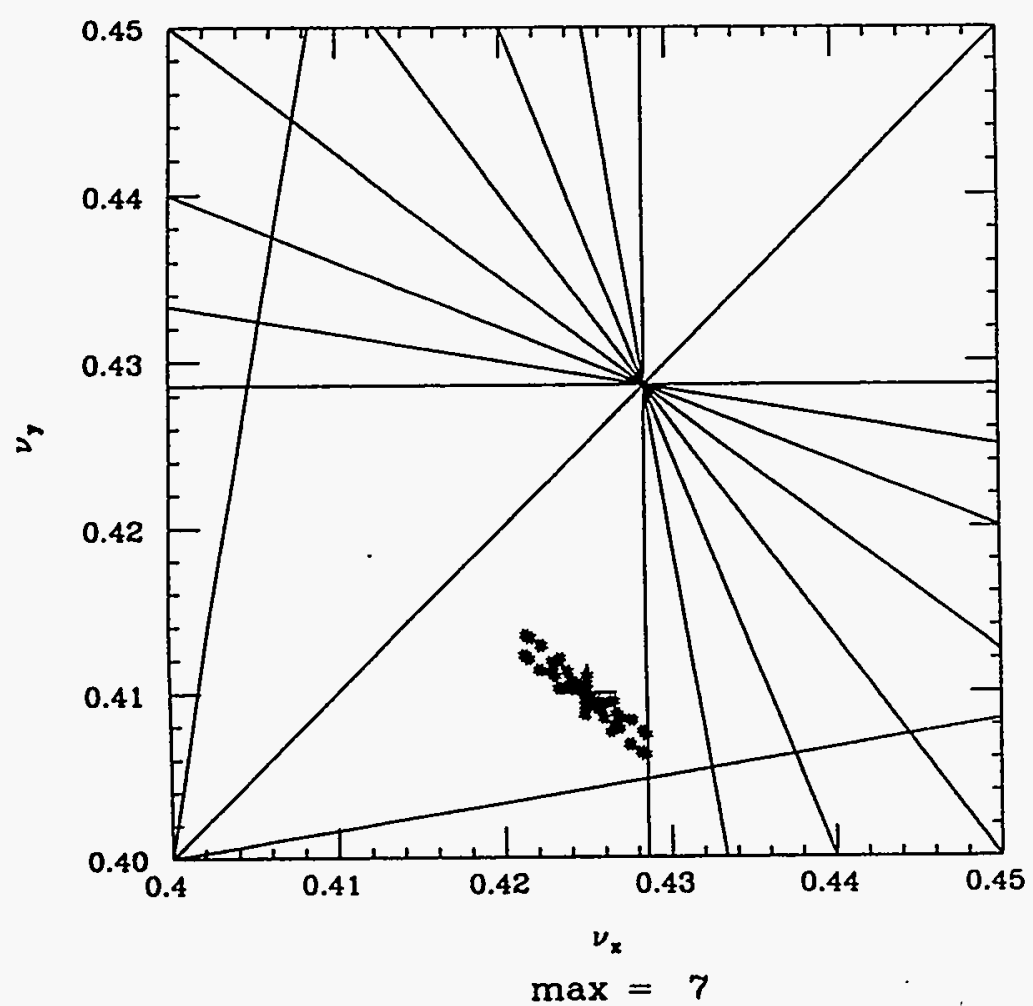

Figure 3: Tune shift $21,4 \mathrm{~cm}$ magnet $x=y=0.400 \mathrm{~cm}$.

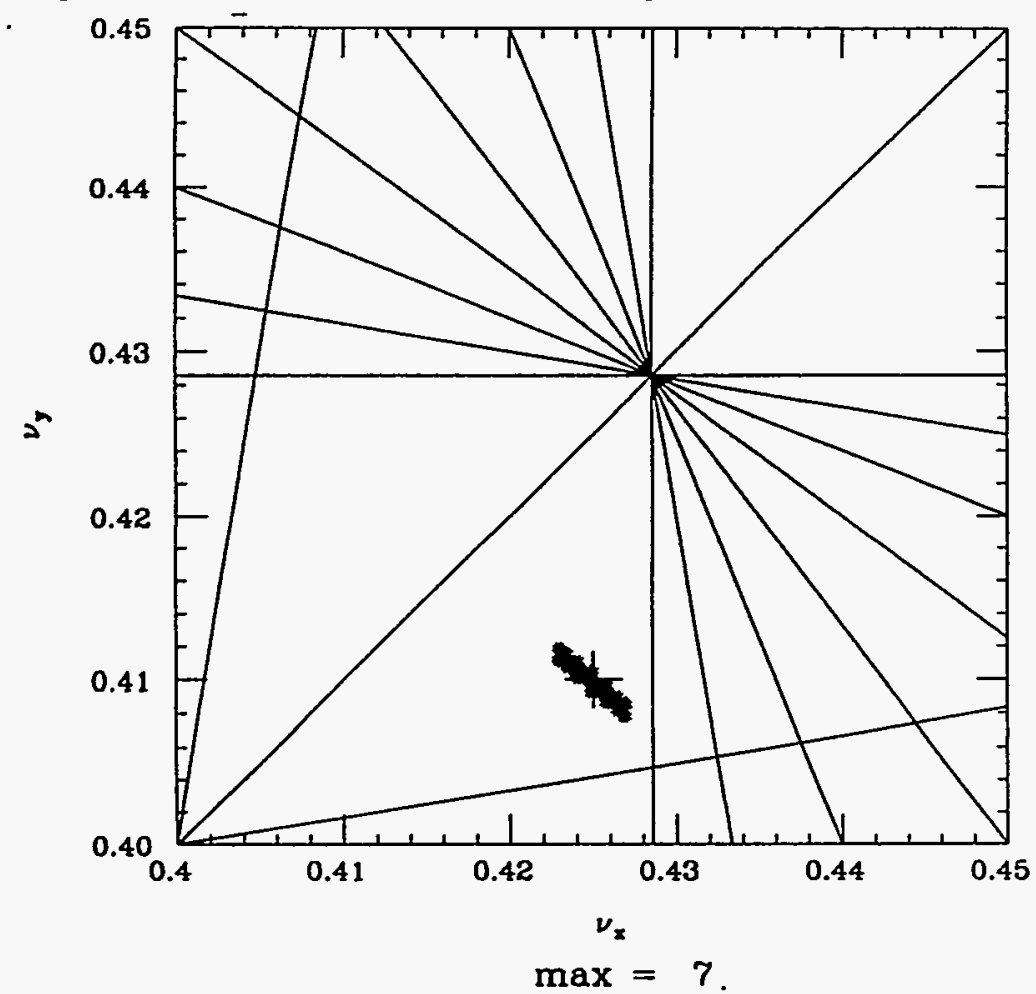

Figure 4: Tune shift 22, $4 \mathrm{~cm}$ magnet $x=y=0.300 \mathrm{~cm}$. 


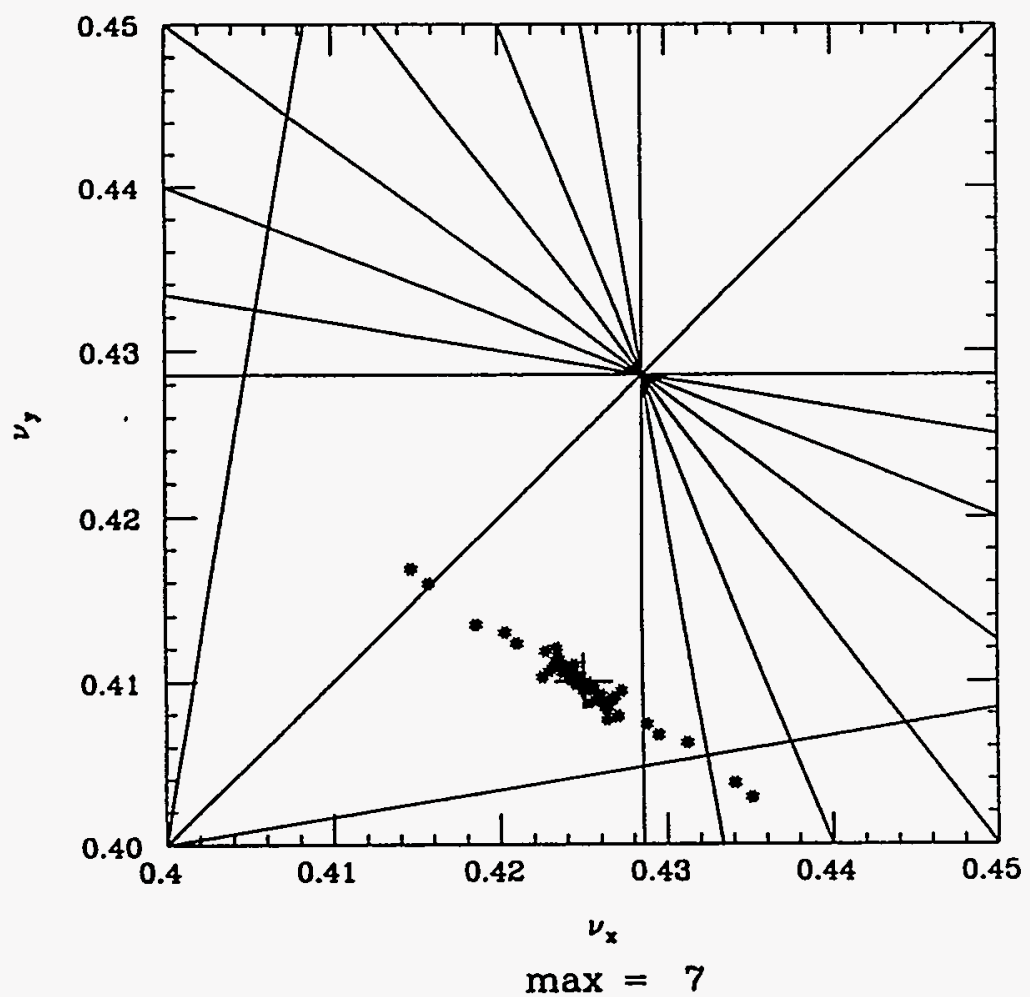

Figure 5: Tune shift 23, $4 \mathrm{~cm}$ magnet $x=y=0.500 \mathrm{~cm}$.

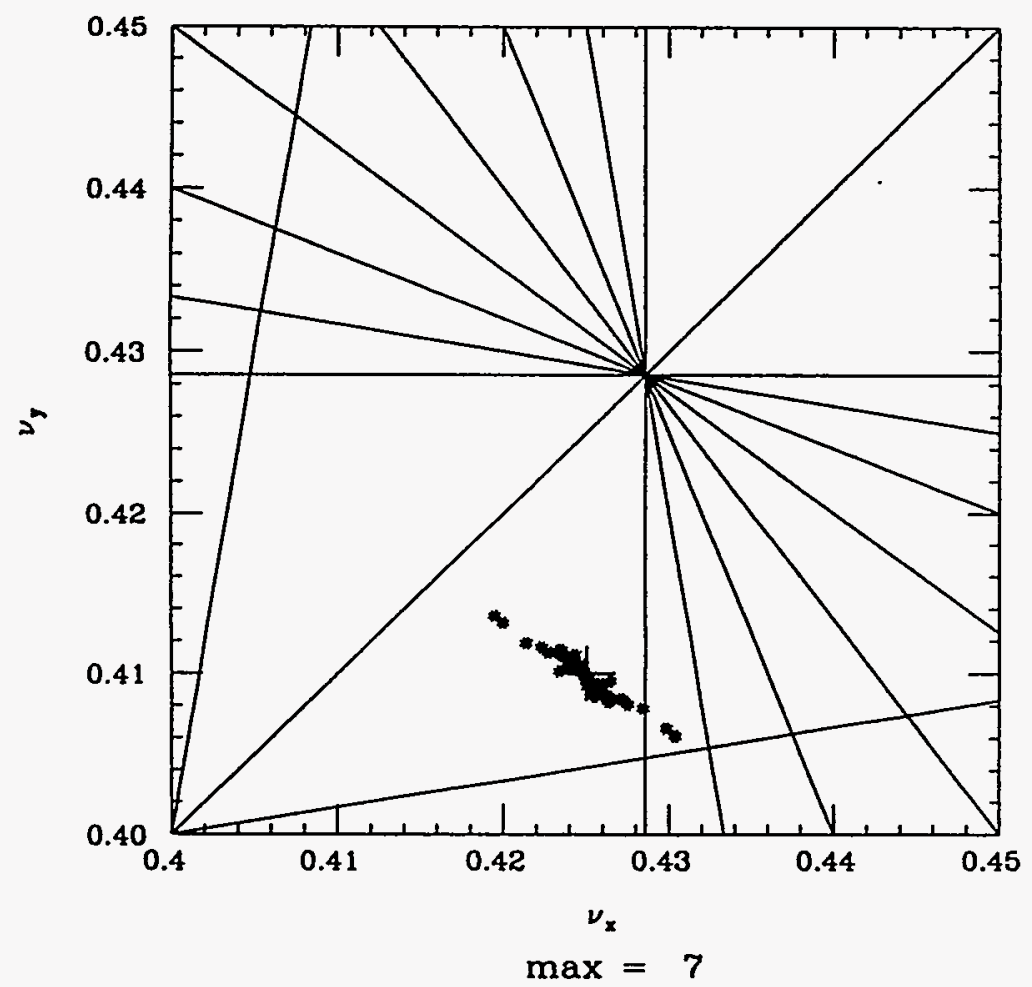

Figure 6: Tune shift 24, $4 \mathrm{~cm}$ magnet $x=y=0.400 \mathrm{~cm}$. 


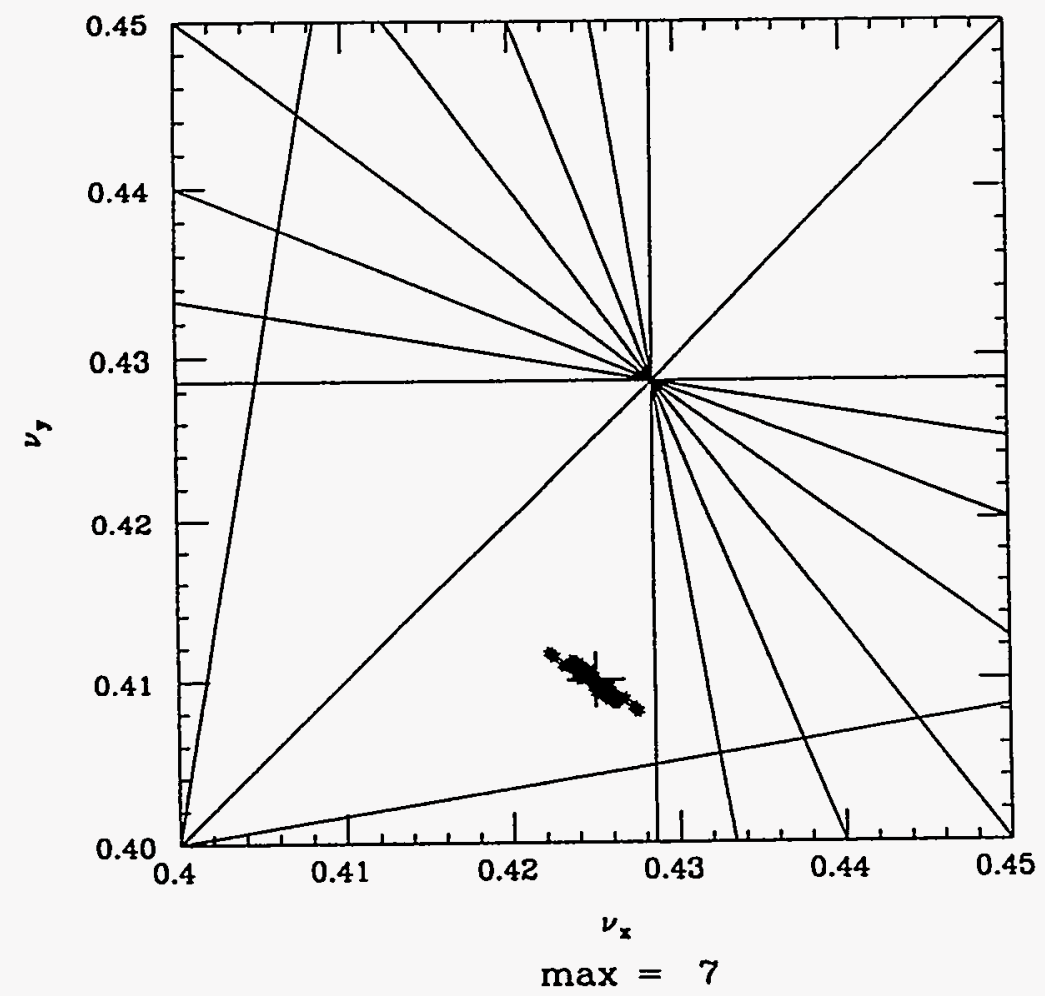

Figure 7: Tune shift 25, $4 \mathrm{~cm}$ magnet $x=y=0.300 \mathrm{~cm}$.

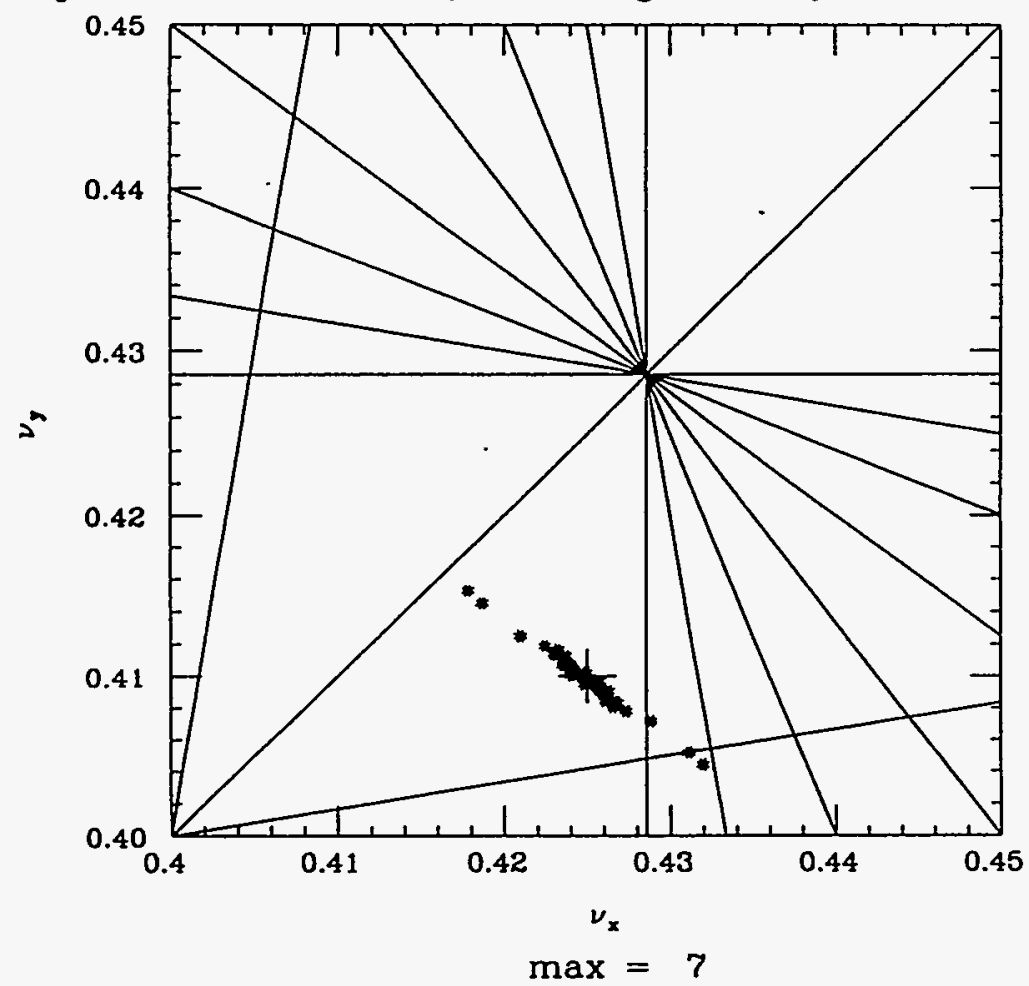

Figure 8: Tune shift $26,4 \mathrm{~cm}$ magnet $x=y=0.500 \mathrm{~cm}$. 


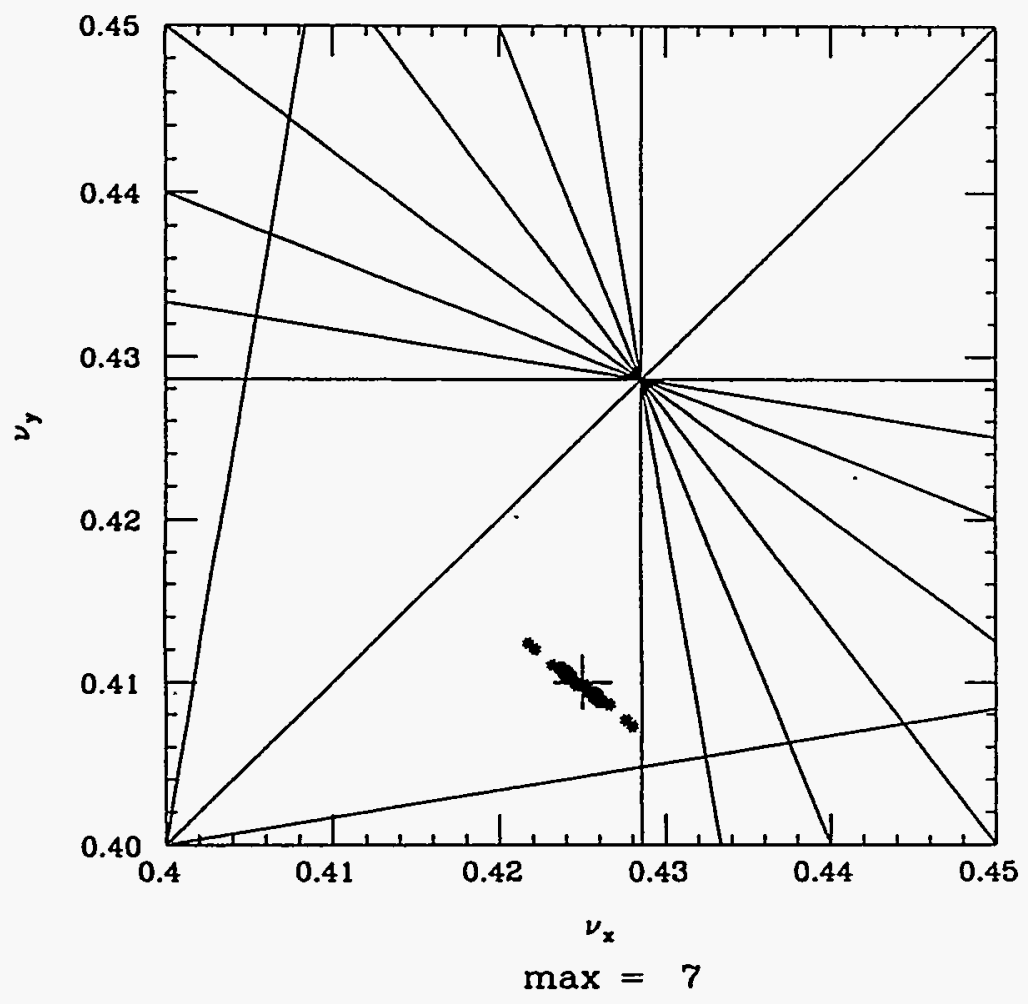

Figure 9: Tune shift 27, $4 \mathrm{~cm}$ magnet $x=y=0.400 \mathrm{~cm}$.

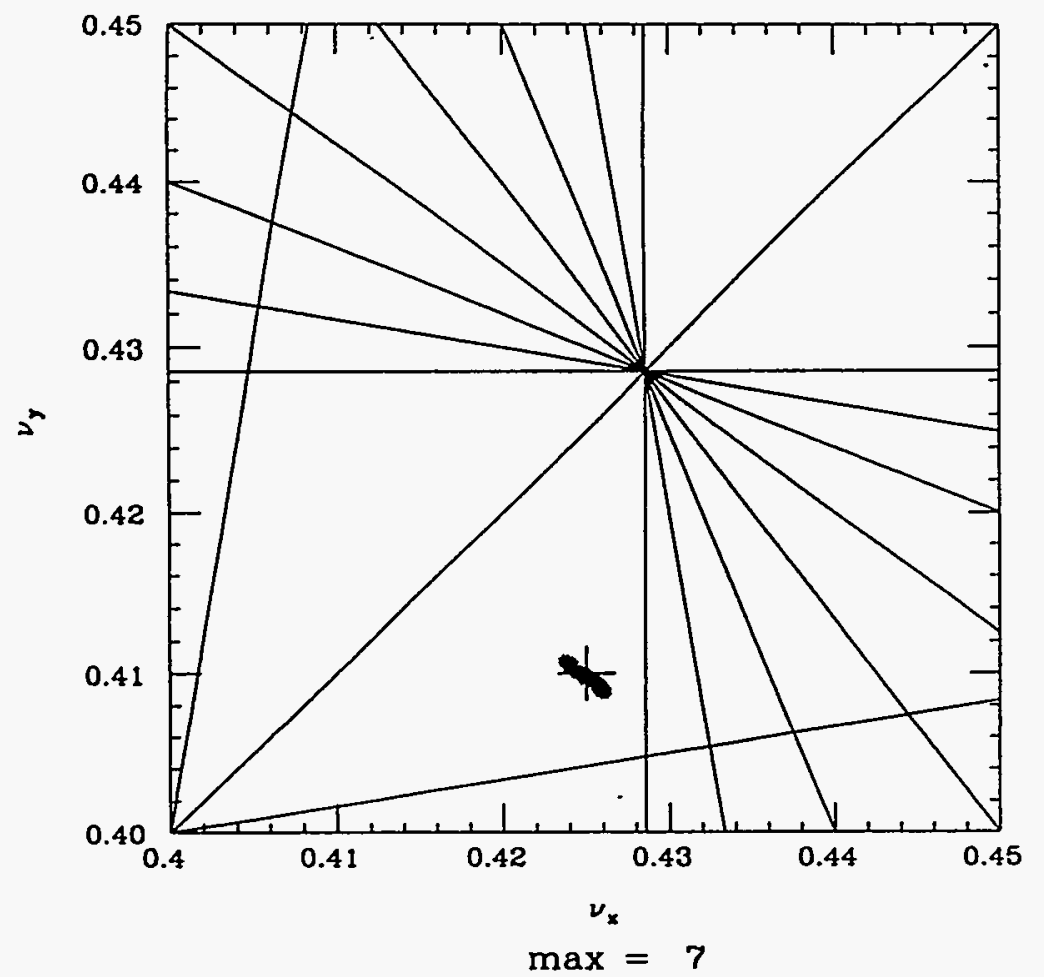

Figure 10: Tune shift $28,4 \mathrm{~cm}$ magnet $x=y=0.300 \mathrm{~cm}$. 


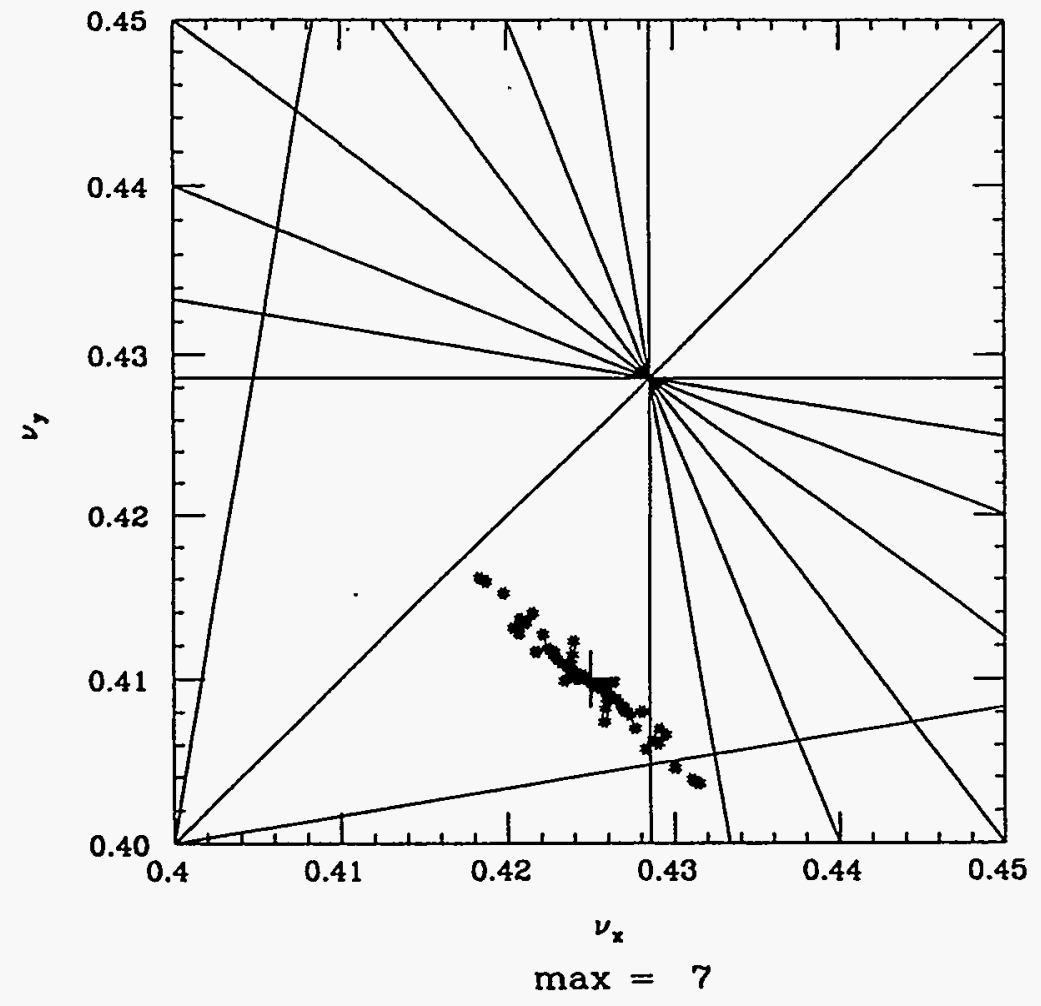

Figure 11: Tune shift $29,4 \mathrm{~cm}$ magnet $x=y=0.500 \mathrm{~cm}$.

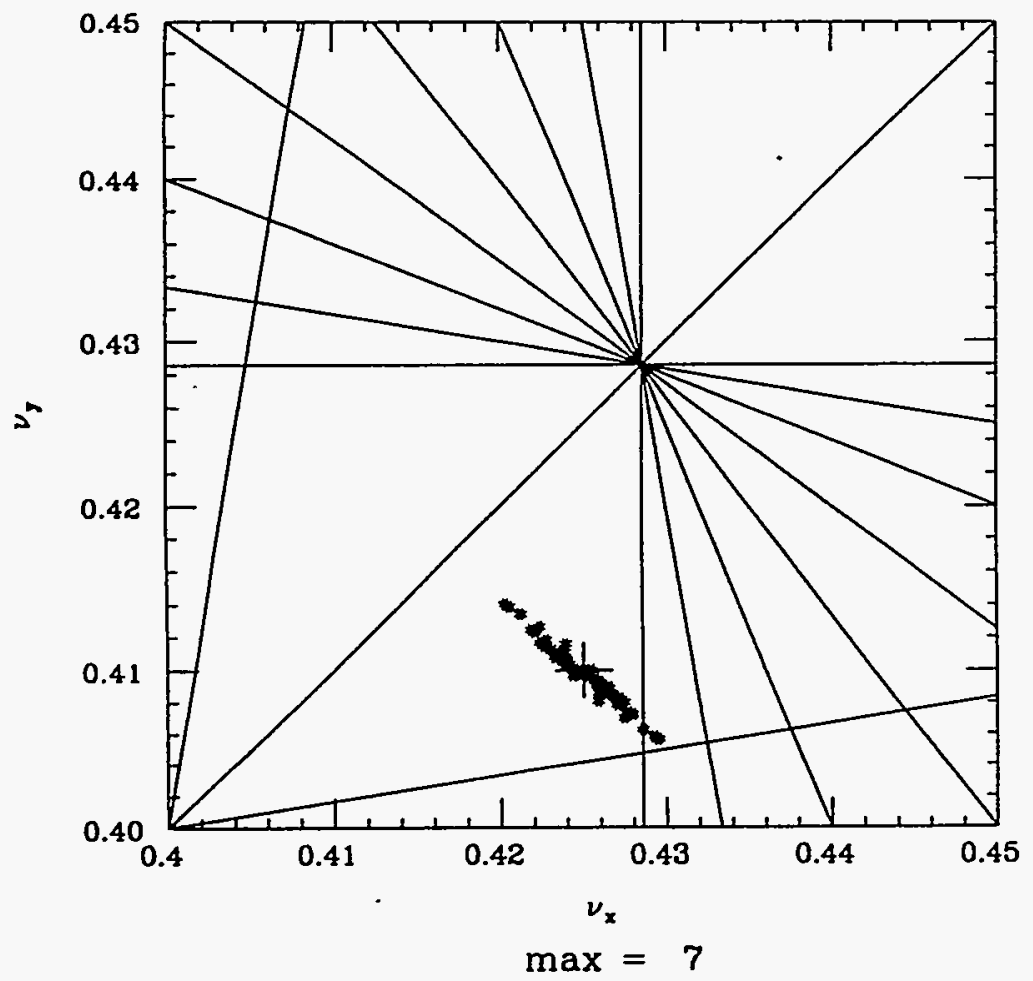

Figure 12: Tune shift $30,4 \mathrm{~cm}$ magnet $x=y=0.400 \mathrm{~cm}$. 


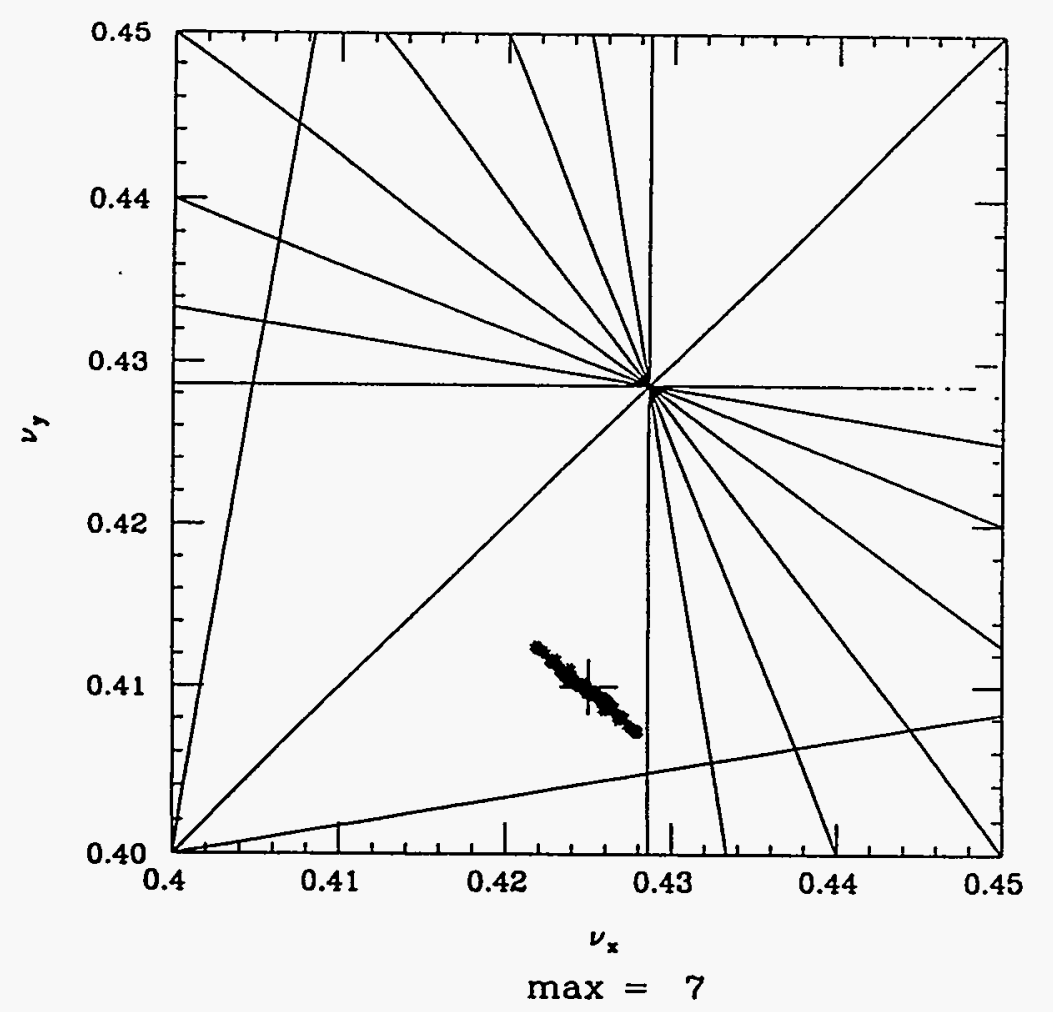

Figure 13: Tune shift $31,4 \mathrm{~cm}$ magnet $x=y=0.300 \mathrm{~cm}$. 